\title{
'FLATTENING' THE PANDEMIC CURVE: HOW PRACTICING INFORMATION HYGIENE COULD HELP
}

\author{
Lazuardyas Zhafran Ligardi \\ Library and Information Science, Universitas Padjadjaran \\ lazuardyas1700I@mail.unpad.ac.id
}

\begin{abstract}
This study presents an insight of the condition of infodemic in Indonesia and to provide solutions by practicing information hygiene could help in mitigating coronavirus disease (COVID-19) infodemic. Public health agencies and the WHO acknowledge infodemiology as an important new research discipline and vital area of practice during a pandemic. The purpose of this study is to provide insights into how the practice of information hygiene could also tackle the COVID-19 pandemic from the point of view of information science. In order to undertake this research, content analysis method is used with qualitative approach. This study concludes that practicing information hygiene by sanitizing before sharing is needed to overcome misinformation and disinformation.
\end{abstract}

Keywords: Infodemic, COVID-19, Information, Pandemic, Information Hygiene

Received 1 February 2021 Accepted 2 February 2022

\section{INTRODUCTION}

In just a few months following the initial appearance of COVID-19 in December 2019, the World Health Organization (WHO) has declared a state of emergency as a pandemic. WHO previously warned the public of an "infodemic" related to news and social media, which it described as an overabundance of information - some accurate and some are inaccurate. [1]

The term infodemic itself has been used to describe the dangers of misinformation during the COVID-19 outbreak. Cinelli, et al. stated that infodemics can accelerate epidemic processes that affect and divide social responses. [2] The spread of infodemic is similar to epidemic, which can spread among humans through information systems, both digital and physical. In this context, it will be difficult for people to find reliable sources and reliable guides when they need them the most. This situation leads to condition called 'information overload'. Yang, et al. [3] defined information overload as difficulty to comprehend a situation and to make choices effectively when one has too much information about that problem.

The COVID-19 pandemic has caused disruption in all sectors of life. An estimated $8 \%$ of the global population is expected to fall into poverty. [4] People are forced to enter an online world and become more familiar with digital devices. However, switching online does not mean without problem. There are many problems that arise in society, one of which is the circulation of hoaxes related to COVID-19. The stakes are higher as COVID-19 is the first social mediaera pandemic.

COVID-19 news and related information about it become common concern. Massive dissemination of information that aggravates the situation will surely be confusing and this potential for misinformation and disinformation is what Vaishya in Gazendam, et al. [1] concern. The phenomenon of the massive distribution of various information about the pandemic needs to be accurate, both in source and content.

In Indonesia, Coronavirus Disease 2019 (COVID-19) vaccines are already under distribution following months of expedited clinical trials, and already out for medical workers 
as priority for the first stage of vaccination. President Joko Widodo received the first dose of China-made Sinovac vaccine on January $13^{\text {th }}$ as he commenced nation-wide vaccine drive. Furthermore Joko Widodo made sure that Sinovac vaccine used in Indonesia is safe and halal (permitted according to Islamic law), also aims to clear doubt and rumors among the masses around this vaccine by including public figures among those who received the first vaccine jab.

Despite vaccination is already having started, the infodemic remains strong. One of the popular rumours is the Sinovac vaccine contains electronic chip that the Chinese government use for doing mass surveillance. Later, this rumour is proven to be false. The aim of this study is to offer ideas as an attempt to give insight on how practicing information hygiene could also battle the COVID-19 pandemic from the perspective of information science. The significance of this study is to give idea as a collective effort to mitigate the COVID-19 crisis in Indonesia. This study will also contribute as a reference for further research on infodemiology, as Infodemiology itself is a relatively new research field.

\section{LITERATURE REVIEW}

Literature review is a recap of research that has been done before on infodemic and its solutions. This literature review also serves another critical function as it helps to identify what focus topic of this study because there is no point in repeating what others have already done. According to [5] in his article titled Literature Reviews: Methods and Applications, there are 8 types of literature review, one of them is narrative review. Narrative review are unstructured audits of writing used to set up a hypothesis based on a research focus. This paper uses narrative review.

The literature selection for this study involves three stages: scanning, curating, and reviewing the articles. There are 3 articles used for this study. (1) Information Overload and Infodemic in the COVID-19 Pandemic by Farooq Rathore and Fareha Farooq of Department of Rehabilitation Medicine, PNS Shifa Hospital, Karachi and Department of Biochemistry, Sir Syed Medical College for Girls, Karachi. This article highlights the concept of infodemic from the perspective of medical worker and how infodemic could lead to information overload. This article published on Journal of Pakistan Medical Association in 2020. (2) COVID-19 vaccine deployment: Behaviour, ethics, misinformation and policy strategies by Royal Society of The British Academy. This study consists of policy recommendations regarding COVID-19 vaccination and everything around it. This study also suggests greater transparency for media organizations to delete harmful content and legal sanctions for individuals or groups who spread misinformation and concludes that the public needs to be encouraged to spot and report misinformation. (3) Health Disinformation \& Social Media by David Robert Grimes of School of Physical Science, Dublin City University Ireland. This study discusses the importance of practicing information hygiene in order to battling disinformation occurred in the realm of social media era. This study concluded that there is a need to put a regulation on social media and to promote awareness and responsibility on using social media.

\section{RESEARCH METHOD}

The method used in conducting this study is the secondary research method by content (content analysis) of written or printed information in mass media, online media, books, and journal articles related to both the infodemic phenomenon and information hygiene. This study uses qualitative approach. Qualitative approach itself is used to develop new knowledge by interpreting and understanding analysis in systematically collected recorded communication. In qualitative research, content analysis emphasizes the efforts to see the content qualitatively, how researchers interpret the content, read symbols, interpret the content of symbolic interactions that occur in communication. The content analysis approach in this literature study will specifically start the analysis with certain symbols, clarify the data with certain criteria and make conclusions with analytical techniques so that the flow of analysis will be clearer. The 
content analysis in this study focuses on the analysis of news and articles about infodemics and its solutions.

\section{FINDINGS AND DISCUSSION Current State of of Indonesia}

The World Health Organization not only hinted at the health risks of COVID-19, but also labeled the situation as an infodemic. COVID-19 is an emerging situation that is continuously developing. At this time of writing, Indonesia's daily new COVID-19 cases is over 10.000 with 27.743 deaths in total while total cases surpassed 1 million. The number of daily cases is fluctuatively increasing week by week. This indicating there is an uncontrolled situation on managing this pandemic. This uncontrolled situation could be caused by scepticism of the people on the existence of COVID-19.

On the other side, Aurelia Virzal in Fajria [6] stated that a trust issue from the young people exist with the government. Many young people are pessimistic about the capacity of the government to cope with the pandemic. Furthermore, because of the false narratives about vaccine and vaccination, a survey undertaken by Saiful Mujani Research \& Consulting (SMRC) in [7] finds that only 37 percent of participant willing to take the vaccine shot. This number is dropped from 54 percent in just a matter of week. 40 percent of respondents, on the other hand, were still unsure as to whether to receive vaccine shots, while the remaining 17 percent reported unaccepting of the vaccination program. [7]. In contrast, Indonesian government stated that Indonesia had to vaccinate 80 percent of the total population in order to develop herd immunity.

That report resonates with chief of Indonesia COVID-19 Response Acceleration Task Force (Satgas COVID-19) Doni Monardo stating 17 percent Indonesians do not believe the existence or feel that they are impossible and very unlikely to be exposed to the Coronavirus [8]. This figure is exceptionally large when compared to the total population of Indonesia of 270 million, meaning that there are 44.9 million people (about twice the population of New York) who do not believe or feel that they will not be exposed to Covid-19. Safe to assume it is for certain that since this masses of people not believing on the danger of COVID-19 in the first place, they would not practice the standard health protocol such as hand washing and keeping physical distance and refusal to wear face masks. This disbelieving manner could worsen COVID-19 cases in Indonesia as they could be silent super-spreader among people with pre-existing comorbidities.

Since now everyone can spread information through social media, misinformation can also be shared more easily, it is also possible that these people behave thay way were influenced by the COVID-19 infodemic in the form of false narratives, conspiracy theories or misleading opinions. Participatory nature of online platforms has allowed disinformation has spread and flourished at unprecedented speeds, creating an atmosphere of uncertainties that has fueled individual and online anxiety and racism [9]. Two of the examples are COVID-19 is a fake conspiracy to benefit big pharmacy business, and China-made Sinovac vaccine contains microchip with evil mass-control intentions. These kinds of misinformation often shared massively by the COVID-19 skeptics. [10].

The rapid development of social media and instant communication is a powerful factor that worsens the spread of infodemics. Infodemics spread swiftly that can affect everyone regardless of place and time. Therefore, our challenge is not only the COVID-19 pandemic, but also an infodemic of COVID-19 which is could be more devastating.

\section{Practicing Information Hygiene}

The WHO said misinformation and disinformation can be "harmful to people's physical and mental health; raise stigmatization; threaten important health gains; and lead to bad behaviour in line with public health measures."" Besides, President Francesco Rocca of the International Federation of Red Cross and Red Crescent Societies outlined misinformation as a "parallel pandemic of mistrust" [11]. 
In the times of hoaxes and rumours overshadow the facts, and the narrative is regularly dominated by fiction, it is important to acknowledge that this is an issue that affects us all and not a simple cognitive or educational problem. The evidence shows that we are historically inadequate at distinguishing between reliable and reprehensible sources because we as humans, we emote first and reflect after; this propensity to react before reflecting is a trojan horse for devious fictions to become established. [12]

Furthermore, Grimes stated that improving our social critical-thinking skills is the only lasting vaccine against this onslaught of harmful narratives. In order to combat the infodemic, we must understand that exposure to misinformation is dangerous, take measures to protect ourselves from being poisoned, and avoid sources of misinformation. We should question ourselves before we perpetuate statements that we find, if they are reputable and verified before we influence others.

Eysenbach [13] in his article titled How to Fight an Infodemic: The Four Pillars of Infodemic Management modeled the fact checking and peer review cycle for everyone to apply in daily life as seen on graphic below.

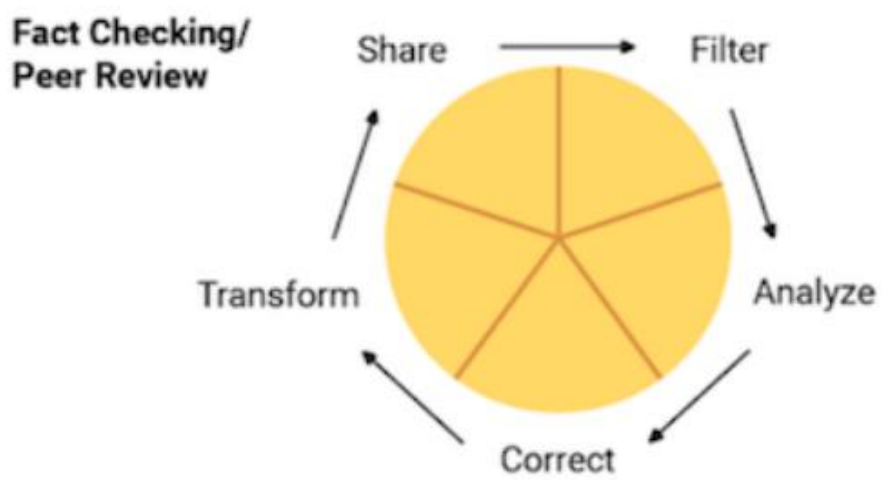

Figure 1. Fact checking cycle includes filtering, analyzing and information correction before sharing.

WHO also posted a guideline in how to identify misinformation and disinformation of COVID-19 in seven steps as given: (1) Source Assessing. To find the clues about the sources of information, for unprofessional graphic design, bad spelling and grammar, or excessive use of all caps or exclamation points can be inconsistent or inaccurate. (2) Checking Headlines. In order to get large numbers of views, headlines can be deliberately sensational or provocative. Read more than just an article's headline; go deeper and look at the whole story. (3) Identify the Author. To see whether they are true or trustworthy, check online for the author's name. (4) Review the Date of the Information Sources to see whether the information is relevant and up to date to current issue. (5) Check the Supporting Evidence. Reliable sources back up their claims with evidence, such as expert quotations or links to statistics or analysis. Verify the professionals are credible and that the narrative is genuinely backed by references. (6) Checking Biases. We do have biases, and they are a factor in how we see what is going on around us. Considering own prejudices and why readers might have been attracted to a certain title or story. (7) Ask the fact-checkers. Consult trusted organisations for fact-checking. In Indonesia, people can turn to Cek Fakta Tempo.co, Masyarakat Anti-Fitnah Indonesia (MAFINDO), or medcom.id Cek Fakta.

As the world moves towards COVID-19 vaccine drive, Director of Digital Health of Meedan, Nat Gyenes said five red flags to look out for in COVID-19 vaccine misinformation: (1) Exaggerated choice of words; (2) Basing information on conspiratorial theories; (3) To look for who is involved in the message whether it contains profiteering on known scientist;

(4) Checking on scientific research findings; (5) Touting traditional medicine as alternative to vaccine with no scientific backup. [14] 


\section{CONCLUSION}

Disinformation polarizes public debate on COVID-19 topics. It generates hate speech; holds the potential civil unrest, abuse or human rights violations; and affects the prospects for democracy, human rights and social unity in the long term.

This information epidemic needs to be 'flattened' with health literacy competencies thus practicing information hygiene. By conducting information hygiene in our daily lives, it is hoped that the Indonesian people feel the urge to 'sanitize' before share and to understand how to differentiate 'healthy' information and 'bad' information so that the people are not affected by the COVID-19 infodemic and are able to pay attention to health protocols and they will be aware of the dangers of this virus so that it can flatten the COVID-19 curve and make the vaccination program successful.

\section{ACKNOWLEDGEMENTS}

The authors thank and appreciate Universitas Padjadjaran and all the experts who provided references and assistance in this study.

\section{REFERENCES}

[1] A. Gazendam, S. Ekhtiari, E. Wong, K. Madden, L. Naji, M. Phillips, R. Mundi and M. Bhandari, 2020. The "Infodemic" of Journal Publication Associated with the Novel Coronavirus Disease. The Journal of Bone \& Joint Surgery, 102 e64. https://doi.org/10.2106/jbjs.20.00610

[2] Cinelli, M., Quattrociocchi, W., Galeazzi, A. et al, 2020. The COVID-19 social media infodemic. Scientific Reports 10 e16598. https://doi.org/10.1038/s41598-020-73510-5

[3] C. Yang, H. Chen and K. Honga, 2013. Visualization of Large Category Map for Internet Browsing, Decision Support Systems 1(35) 89-102. https://doi.org/10.1016/S0167-9236(02)00101-X

[4] A. Sumner, C. Hoy and E. Ortiz-Juarez, Estimates of the impact of COVID-19 on global poverty, 2020. WIDER Working Paper (43) 1-14. https://doi.org/10.35188/UNUWIDER/2020/800-9

[5] S. J. Stratton, 2019. Literature Reviews: Methods and Applications, Prehospital and Disaster Medicine 34( 4) 347-349. https://doi.org/10.1017/S1049023X19004588

[6] F. Hana, Indonesian Youth Don't Care About COVID-19? Research Explains Why, https://www.feb.ui.ac.id/en/blog/2020/10/12/indonesian-youth-dont-care-about-covid19-heres-the-research/, 2020. (Accessed 18 January 2020).

[7] R. Fachriansyah, Majority of Indonesians unsure about COVID-19 vaccination, survey finds, https://www.thejakartapost.com/news/2020/12/23/majority-of-indonesiansunsure-about-covid-19-vaccination-survey-finds.html, 2020. (Accessed 21 January 2021)

[8] Merdeka, BPS Sebut 44,9 Juta Warga Tak Percaya Corona, Satgas Berharap Banyak pada Media, https://www.merdeka.com/peristiwa/bps-sebut-449-juta-warga-takpercaya-corona-satgas-berharap-banyak-pada-media.html, 2020. (Accessed 21 January 2021).

[9] S. M. Sloan, Behind the 'Curve': COVID-19, Infodemic, and OralHistory, 2020. The Oral History Review 47(2) 193-202. https://doi.org/10.1080/00940798.2020.1798256

[10] J. Nugroho, Indonesia's COVID-19 Conspiracy Theories, https://newnaratif.com/journalism/indonesias-covid-19-conspiracytheories/share/revxanqve/ac54acb4b5289a1342f6e71089288e0b/, 2020. (Accessed 20 January 2021).

[11] International Federation of Red Cross and Red Crescent Societies, IFRC: Success of COVID-19 vaccine relies on our ability to address "mistrust pandemic", 
https://media.ifrc.org/ifrc/press-release/ifrc-success-covid-19-vaccine-relies-abilityaddress-mistrust-pandemic/,2021. (Accessed 21 January 2021)

[12] D. R. Grimes, 2020. Health Disinformation \& Social Media. Science and Society. 21(11) e51819. https://dx.doi.org/10.15252\%2Fembr.202051819

[13] G. Eysenbach, 2020. How to Fight an Infodemic: The Four Pillars of Infodemic Management, Journal of Medical Internet Research. 22(6) e21820.

https://dx.doi.org/10.2196\%2F21820

[14] N. Hanopol and K. Ting, VERA FILES YEARENDER: Five red flags to look out for in COVID-19 vaccine misinformation, https://verafiles.org/articles/vera-files-yearenderfive-red-flags-look-out-covid-19-vaccin ,2020. (Accessed 19 January 2020). 